\section{Endoscopic dacryocystorhinostomy: a personal technique}

The lids are examined and laxity tested. At the biomicroscope, the size of the puncta and relation to the tear film are noted. The inner canthus is massaged. Reflux of muco-pus indicates a mucocoele.

An updated Jones I test is performed. Fluorescein is instilled and may demonstrate pooling of tears. The nasal cavity is then inspected. The short $60 \mathrm{~mm} 0^{\circ}$ rigid Hopkins endoscope that fits on an ophthalmoscope handle is the most convenient. If fluorescein is seen at the opening of the duct inferior to the inferior turbinate, then the epiphora is secondary to increased tear production. Attention is paid to the size and shape of the nasal cavity as this will determine the ease of surgery. A deviated nasal septum or large turbinates could require surgery in order to improve access. The presence of polyps can be noted.

After a couple of drops of amethocaine, the inferior punctum is dilated with a Nettleship dilator and a $0 / 00$ probe is passed down the common canaliculus and manoeuvred until a 'hard stop' is felt. If a 'soft stop' is felt, it indicates that there is a stenosis within the common canaliculus and this is not a suitable case for endo DCR. With the lacrimal canula within the distal common canaliculus, saline is slowly but firmly injected. This is continued until clear fluid refluxes up. More saline is then injected. Occasionally, a partial stenosis can be overcome and the epiphora relieved in this way.

\section{The role of CT DCG}

\section{A dacryocystogram (DCG) or CT DCG is} probably not mandatory in all cases. However, CT DCG is especially useful in epiphora as a result of mid-facial trauma, after surgery or radiotherapy for sinus neoplasms, and of interest in establishing the cause of a failed external DCR. It will identify coexisting sinus disease, reveal anatomical variants such as anteriorly-placed ethmoidal air cells and indicate the thickness of the bone to be resected.
G.A. Shun-Shin Wolverhampton Eye Infirmary Compton Road Wolverhampton WV3 9QR, UK e-mail: eyecons@shunshin. softnet.co.uk 


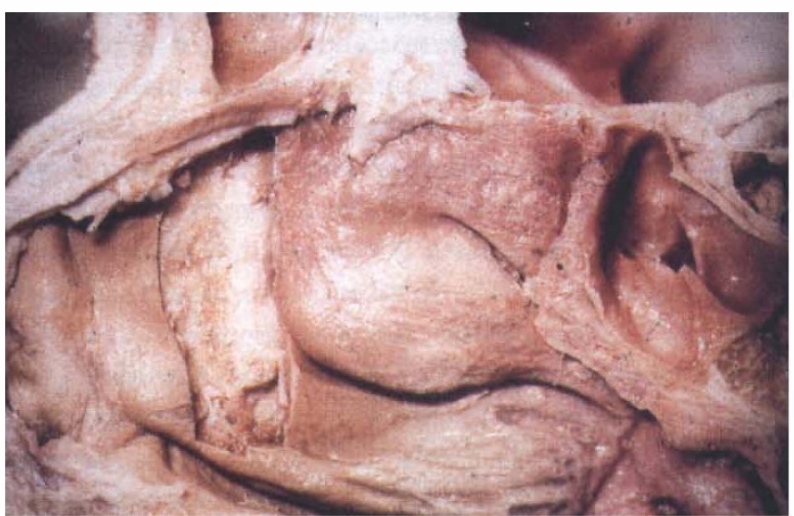

(a)

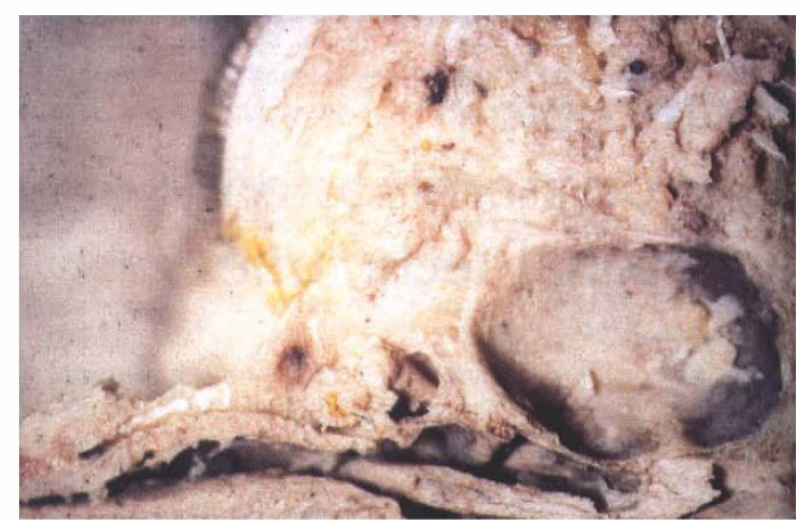

(b)

Fig. 1. Anatomical dissections. (a) A view of the lateral wall of the nose. Mucosa and bone have been removed to reveal the lacrimal sac and duct anterior to the middle turbinate. Note that during surgery the middle turbinate is a key landmark. (b) A cross-section at the level of the middle turbinate. The sac, outlined in yellow, lies behind the ridge formed by the frontal process of the maxilla. Part of this frontal process is removed during the operation to provide adequate visualisation of the sac.

\section{Surgical technique}

The procedure can be performed under local or general anaesthesia. Hypotensive anaesthesia is not required. The guiding principle in a minimally invasive procedure is to minimise trauma and blood loss, which will increase post-operative fibrosis and cause the ostomy to close. Bleeding makes the operation difficult and dangerous.

Before anaesthesia, the head of the patient is supported as it is kept hyperextended over the top of the table. With the nose pointing straight up, $1 \mathrm{ml}$ of a Moffat mixture of $1 \mathrm{ml}$ of adrenaline 1/1000, $2 \mathrm{ml}$ of $4 \%$ cocaine and $3 \mathrm{ml}$ of $8.4 \%$ bicarbonate is trickled in. This is repeated with the head pointing left and right. This will cause blanching of the mucosa and lessen bleeding if the wall of the nose is scraped inadvertently by the instruments. The operating table is tilted up by $20^{\circ}$ to lessen bleeding. The punctum is dilated, and a Bowman ' 0 ' probe is passed until the hard stop is felt, then angled down and medially and a little posteriorly aiming to reach the lower part of the lacrimal sac. This is lower than the surgeon used to conventional DCR would expect. The lower the ostomy, the less the chance of a post-operative sump syndrome.

A 26 gauge light pipe as used in vitrectomy is then passed. The light within the nasal cavity is seen using a rigid $0^{\circ}$ Hopkins endoscope. It will be seen to lie just behind the ridge formed by the frontal process of the maxilla and near the root of the medial turbinate. This is the key anatomical landmark to recognise. It confirms that a false passage has not been created by the light pipe. This is easily done in cases where there has been previous surgery. Do not venture posterior to the light pipe as entry into the orbit is possible.

The mucosa around and anterior to the light over the frontal process of the maxilla is infiltrated with $1 \mathrm{ml}$ of lignocaine with $1 / 80000$ adrenaline. An oval cut $2 \mathrm{~cm} \times 1 \mathrm{~cm}$ into the mucosa is made with a sickle knife. Bleeding mainly occurs from the edge of the cut mucosa, so that a smooth oval is aimed for. The mucosa is elevated off the bone with mucosal elevators and removed in one piece (Fig. 2a).

It is important to remove part of the frontal process of the maxilla. This allows better access and visualisation of the lacrimal sac. This is the fundamental difference between surgical and laser-assisted endo DCR. The laser can only ablate the much thinner lacrimal bone. Using an osteotome and hammer, a piece of bone of at least $0.5 \mathrm{~cm}$ square is removed. A drill sprays bone and blood and obscures the view down the endoscope slowing down the procedure. The fragile lacrimal bone may now be broken off piecemeal using the tip of the osteotome (Fig. $2 b$ ). The lacrimal sac, illuminated from inside, is now well seen. The sac is opened with a sickle knife and a $5 \mathrm{~mm}$ window is made with scissors (Fig. 2c). It is important not to pull or grab the sac mucosa as this may traumatise the rest of the sac, which ideally should be left undisturbed. Any mucus and debris is irrigated and aspirated out of the sac (Fig. 2d). The interior of the sac is inspected for stones or tumour. An O'Donoghue silicone tube is passed through the upper and lower puncta and pulled out of the sac under direct vision. It is good practice to grasp the tip of the bodkin with the forceps. This covers the sharp end of the bodkin and prevents inadvertent scraping of the mucosa as the bodkin is pulled out (Fig. 2e).

A $1.5 \mathrm{~cm}$ square of Silastic sheeting is button-holed over the two ends of the Silastic tube and placed as close to the sac as possible. The original idea was to funnel this into the ostium to keep it open. In practice this is difficult to achieve. It does, however, prevent post-operative adhesions and allows easier retrieval of the stent postoperatively. It makes extrusion of the tubes upwards at the inner canthus unlikely. A black silk suture is tied round the silicone tubes. Aspirating blood and fluid from the floor of the nose will spare the patient coughing up altered blood post-operatively. Packing the nose is unnecessary and needlessly uncomfortable. A broad spectrum antibiotic is given for 5 days prophylactically. 


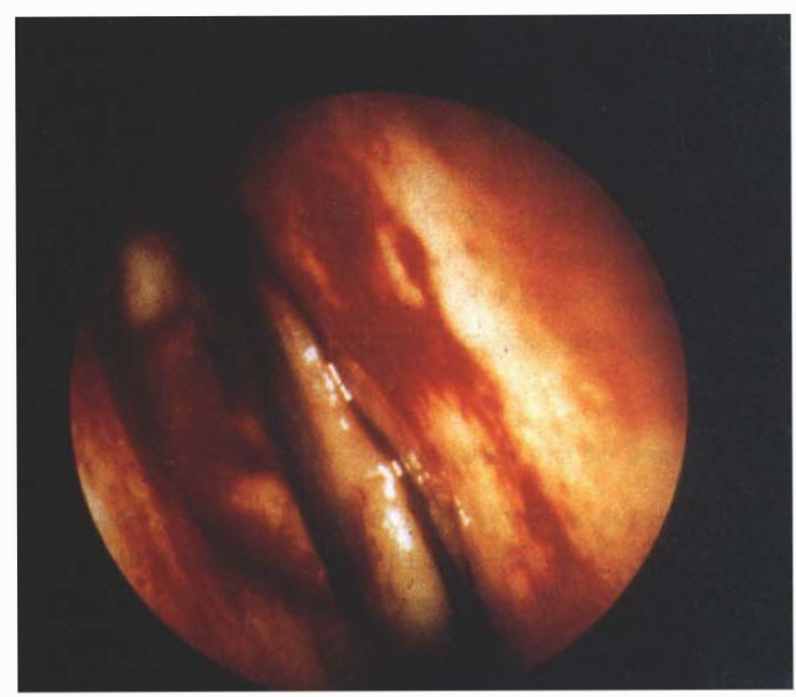

(a)

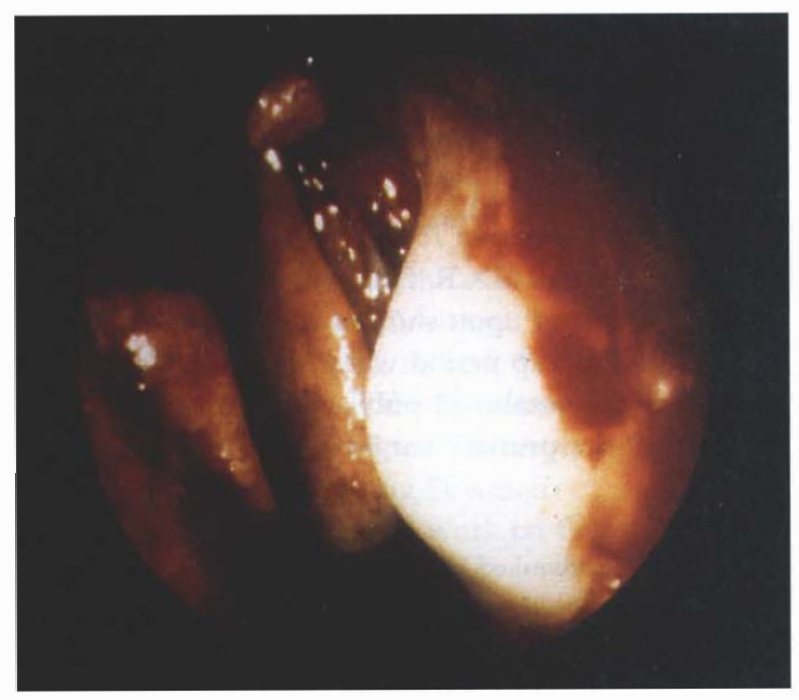

(c)

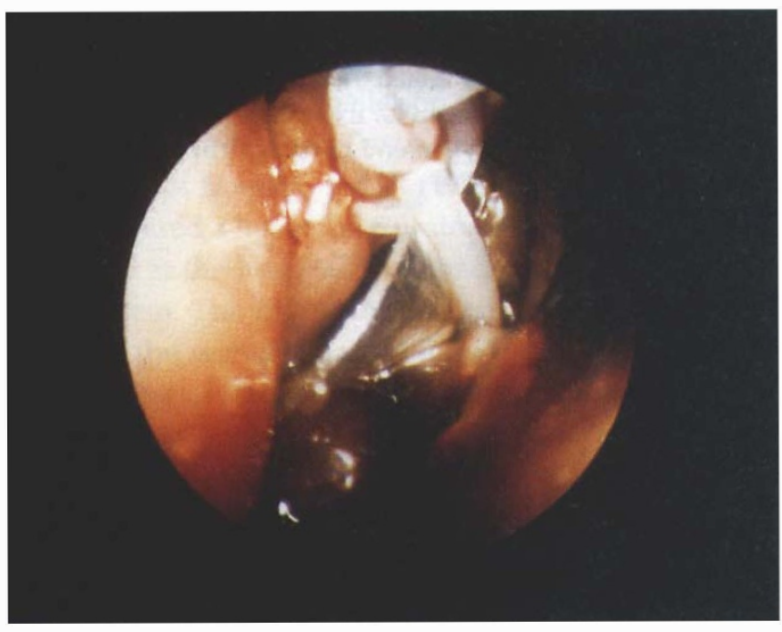

(e)

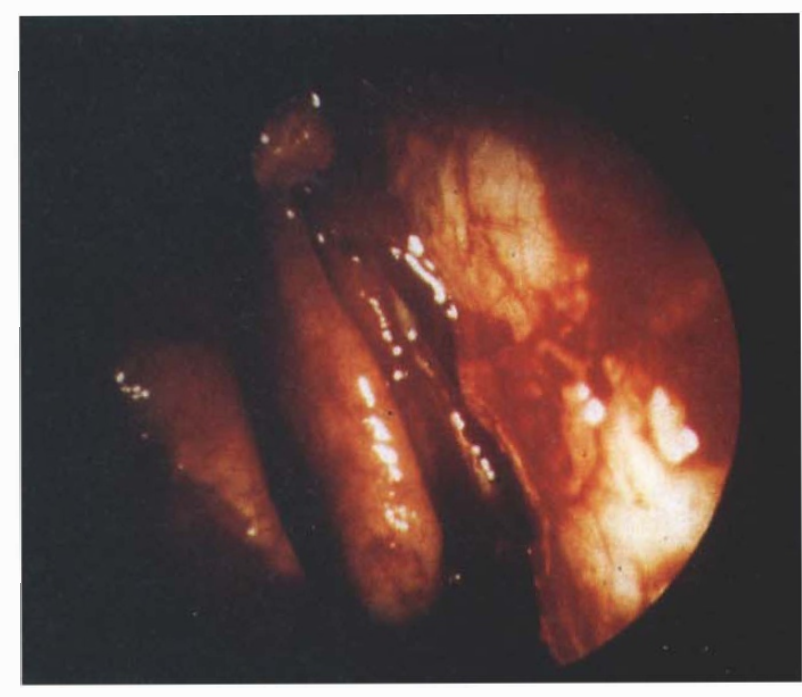

(b)

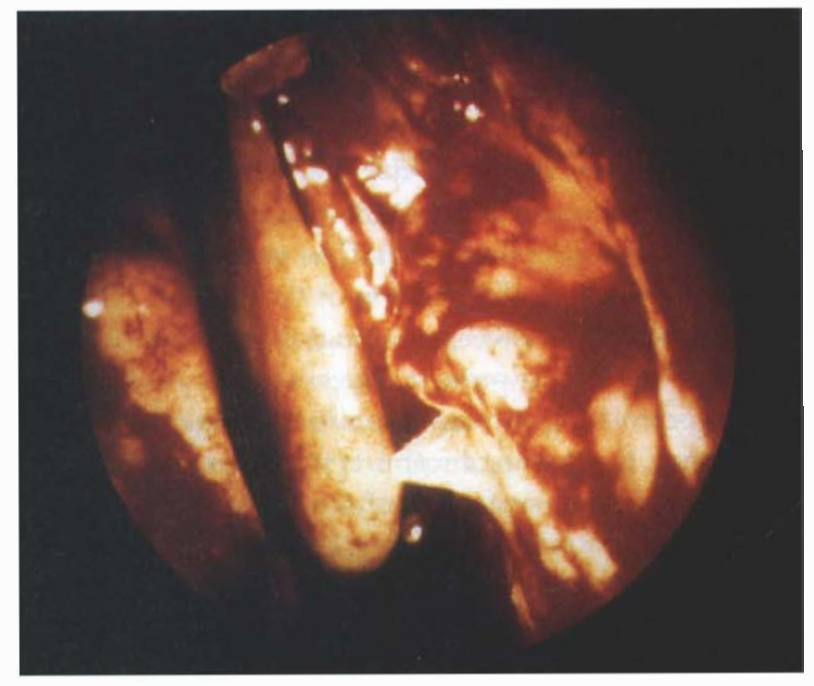

(d)

Fig. 2. Operative photographs. (a) The mucosa has been stripped from the frontal process of the maxilla. (b) Part of the frontal process of the maxilla has been removed to showe the sac. (c) The lacrimal sac is incised with release of muco-pus from the sac. (d) Gramulation tissue can be seen within the sac. (e) The O'Donoghue tube is in situ. 


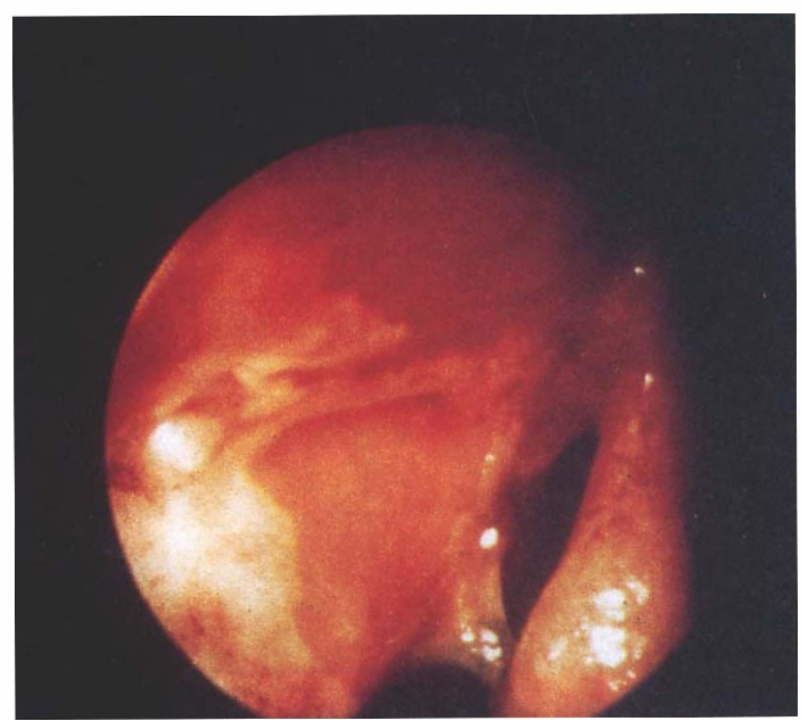

Fig. 3. A typical 6 week post-operative result. Fluorescein can be' se'n percolating out through the ostium.

Chloramphenicol eye drops are prescribed three times a day for 2 weeks. Ointment should be avoided to prevent clogging of the nasolacrimal system.

In most cases, the eye is dry the next day. The inner canthus is inspected to check that the Silastic tube is not tight and distorting the puncta. The patient is seen 1 week later to check the position of the silicone tube and this is removed at 6 weeks. Syringing is performed to flush out any debris present. Fluorescein is instilled and is seen percolating through the ostium (Fig. 3).

Sometimes, the fluorescein spurts into the nose with each blink, a vivid demonstration of the lacrimal pump in action. Any granulation tissue is cauterised using silver nitrate. The patient is seen at $2-4$ weeks later, syringing is again performed and the patient is discharged if all is well.

\section{Learning the technique}

Success is highly dependent on a thorough knowledge of nasal anatomy. Time is well spent studying dissected specimens in the anatomy department. Familiarity with the highly variable appearances of the nose is necessary. It is strongly recommended that the ophthalmologist wishing to learn the technique spend time with an experienced ENT colleague who specialises in functional endoscopic sinus surgery. The ophthalmologist should aim to perform 30 or so procedures under supervision before operating solo. Whilst the ophthalmologist and his ENT colleague can learn from each other in the early stages, it is not cost-effective to have two specialists operating on the straightforward cases. However, collaboration in cases resulting from severe mid-facial trauma and after surgery for carcinoma is beneficial.

\section{Advantages of the technique}

The technique is faster than an external DCR and takes half an hour. It is safe as it can be performed under local anaesthesia or general anaesthesia without hypotension. There is no external scar, blood loss is $10-20 \mathrm{ml}$ and there is minimal post-operative discomfort. In the majority of cases there is no reflux of air when the patient blows his or her nose, demonstrating that the functional anatomy is preserved.

\section{Success rate}

Several authors have published their success rate of the technique. Jokinen and Karja ${ }^{1}$ had a success rate of $83 \%$ for 126 primary endo DCRs in 109 patients. Metson ${ }^{2}$ has shown a success rate of $75 \%$ for secondary endo DCRs after failed external DCR. Our own series of the first 40 patients ${ }^{3}$ operated upon showed a success rate of $86 \%$; the mean follow-up period was 18 months. This compares with combined published figures for external DCR of $91 \%$ for primary surgery and $81 \%$ for secondary surgery. ${ }^{4}$

$\mathrm{Mr}$ S. Rollason is thanked for the anatomical specimens in Fig. 1a and $\mathrm{b}, \mathrm{Mr} \mathrm{H}$. Whittet for Fig. 2a-e.

\section{References}

1. Jokinen K, Karja J. Endonasal dacryocystorhinostomy. Arch Otolaryngol 1974;100:41-4.

2. Metson R. Endoscopic surgery for lacrimal obstruction Otolaryngol Head Neck Surg 1991;104:473-9.

3. Watters GWR, Whittet HB, Shun-Shin GA, Milford CA. Endoscopic transnasal dacryocystorhinostomy: long term results. Min Invas Ther Allied Technol 1996;5:505-10.

4. Shun-Shin GA, Thurairajan G. External dacryocystorhinostomy: an end of an era? Br J Ophthalmol 1997;81:716-7. 